\title{
Functional Polymers for Drug Delivery Systems in Nanomedicines
}

\author{
Eun Seong Lee', Ji Hoon Kim², Jeongmin Yun², Kyung Soo Lee², Ga Young Park², \\ Beom-Jin $\mathrm{Lee}^{3}$ and Kyung Taek $\mathrm{Oh}^{2 \dagger}$ \\ ${ }^{1}$ Division of Biotechnology, The Catholic University of Korea, 43-1 Yeokgok 2-dong, Wonmi-gu, \\ Bucheon-si, Gyeonggi-do 420-743, Republic of Korea \\ ${ }^{2}$ College of Pharmacy, Chung-Ang University, 221 Heukseok dong, Dongjak-gu, Seoul, 156-756, Republic of Korea' \\ ${ }^{c}$ Bioavailability Control Laboratory, College of Pharmacy, Kangwon National University, Chuncheon, Korea.
}

(Received September 2, $2010 \cdot$ Revised October 4, $2010 \cdot$ Accepted October 5, 2010)

\begin{abstract}
Polymeric based nanomedicines have been developed for diagnosing, treating, and preventing diseases in human body. The nanosized drug delivery systems having various structures such as micelles, nanogels, drug-conjugates, and polyplex were investigated for a great goal in pharmaceutics: increasing therapeutic efficacy for diseases and decreasing drug toxicity for normal tissues. The functional polymers used for constituting these drug delivery systems should have several favorable properties such as stimuli-responsibility and biodegrdability for controlled drug release, and solublization capacity for programmed drug encapsulation. This review discusses recent developments and trends of functional polymers (e.g., pH-sensitive polymers, biodegradable polymers, and cationic polymers) used for nanosized drug carriers.
\end{abstract}

Key words - functional polymers, nanomedicine, $\mathrm{pH}$-sensitive, biodegradable, cationic polymers

Recently polymers have attracted significant attention in the area of tissue engineering, cosmetics, nanotechnology, and pharmaceutics. Polymer biomaterials have been used for various biomaterial applications such as implantable medical device, artificial organ, dental implantation, suture, contact lens, diagnostics device, and drug delivery system (Ratner et al. 1976). In particular, a wide variety of polymer biomaterials have been utilized as a key component in various pharmaceutical formulations and devices that are routinely used for controlled drug delivery systems, and have been intensively evaluated for the delivery of drugs, proteins, genes and diagnosis agents (Allen et al. 1999; Torchilin 2002; Jeong et al. 2007). The controlled release polymer systems can be classified according to the mechanism that controls the release of the therapeutic agent (Table I).

These polymer-based systems have several favorable characteristics such as easy fabrication of nanosized drug delivery systems (DDS), practical solublization of drugs, and intelligent manipulation of drug release (Langer 1980; Uhrich et al. 1999; Neuse 2008). For example, nanosized polymeric systems called as magic bullet (Ehrlich 1960), Trojan horse (Dietz et al. 2004), and stealth particle (Moghimi et al. 2001) encapsulate drugs and carry out drugs to disease sites (Couvreur et al. 2006). These nanovehecles have been marvelously investi-

${ }^{\dagger}$ Corresponding Author :

Tel : +82-2-824-5617, E-mail : kyungoh@cau.ac.kr

DOI : $10.4333 /$ KPS.2010.40.S.045 gated to increase the efficacy and safety of therapeutic agents (Torchilin 2000; Ruenraroengsak et al. 2010).

Several excellent reviews are currently available in the literature on polymer synthesis, stimuli-responsive drug carrier, polymer-drug conjugate, ligand/antibody-bearing drug carriers, and PEGylated nanocarrier (Langer 1980; Uhrich et al. 1999; Duncan 2003; Oh et al. 2007a; van Vlerken et al. 2007; Neuse 2008). This review aims to address the functional polymers utilized for nanomedicine formulations, which covers $\mathrm{pH}$-sensitive polymers, biocompatible/biodegrdable polymers, and cationic polymers (as gene carriers).

\section{Nanomedicine Based on Polymeric DDS}

Nanomedicine as a large subject area is generally defined as the medical application of nanotechnology and includes the design and manipulation of nanoparticles for diagnosing, treating, and preventing diseases in the human body (Moghimi et al. 2005). Figure 1 illustrates the nanomedicines related to nanotechnology and molecular nanocarriers. In pharmaceutics, nanovehicles have been developed for delivery of drugs, genes, proteins, and imaging agents. Biomaterials used as this drug delivery are generally polymers, lipids, and carbon assembles. Among them, polymer-based technologies can be selected for the specific applications. Amphiphilic block copolymers composed of hydrophobic block and hydrophilic block have been widely investigated due to their unique characteristics such as formation of a spherical structure with nano- 
Table I. Controlled Release Drug Delivery Systems (DDS)

\begin{tabular}{|c|c|c|}
\hline Class & Systems & Application \\
\hline Diffusion-Controlled DDS & Reservoir Systems and Monolithic Systems & $\begin{array}{l}\text { Ocusert }^{\circledR}, \text { Progestasert } \\
\left(\text { Nicoderm }^{\circledR}, \text { Estraderm }^{\circledR}\right)\end{array}$ \\
\hline \multirow[t]{2}{*}{ Water Penetration Controlled DDS } & Osmotic Controlled Systems & Oros $^{\circledR}$, Scutrim $^{\circledR}$, Osmet $^{\circledR}$ \\
\hline & Swelling Controlled Systems & Geomatrix $^{\circledR}$ \\
\hline \multirow[t]{2}{*}{ Chemically-Controlled DDS } & Biodegradable Reservoir and Monolithic Systems & PLGA $\left(\right.$ Superfact $^{\circledR}$ Depot, Eligard $^{\circledR}$ ) POE \\
\hline & $\begin{array}{l}\text { Biodegradable Polymer Backbones with Pendant } \\
\text { Drugs }\end{array}$ & Drug-poly(N5-hydroxypropyl-L-glutamate) \\
\hline \multirow[t]{3}{*}{ Responsive DDS } & Physically- and Chemically-Responsive Systems & ReGel $^{\circledR}$, OncoGel $^{\circledR}$, Carbomer $^{\circledR}$, Eudragit $^{\circledR}$ \\
\hline & $\begin{array}{l}\text { Mechanical, Magnetic, or Ultrasound-Responsive } \\
\text { Systems }\end{array}$ & \\
\hline & Biochemical-Responsive : Self-regulated Systems & \\
\hline \multirow[t]{4}{*}{ Particulate DDS } & Microparticulates & Microcapsule, Microsphere \\
\hline & Polymer-Drug Conjugates & $\begin{array}{l}\text { Adagen }^{\circledR}, \text { PEG-INTRON } \\
\text { HPMA copolymer-doxorubicin }\end{array}$ \\
\hline & Polymer Micelle systems & Sp1049C, NK911 \\
\hline & Liposome Systems & Doxil $^{\circledR}$, AmBisone $^{\circledR}$ \\
\hline
\end{tabular}

This table was modified from the original table in ref. (Ratner et al. 1976)

\section{Nanomedicines}

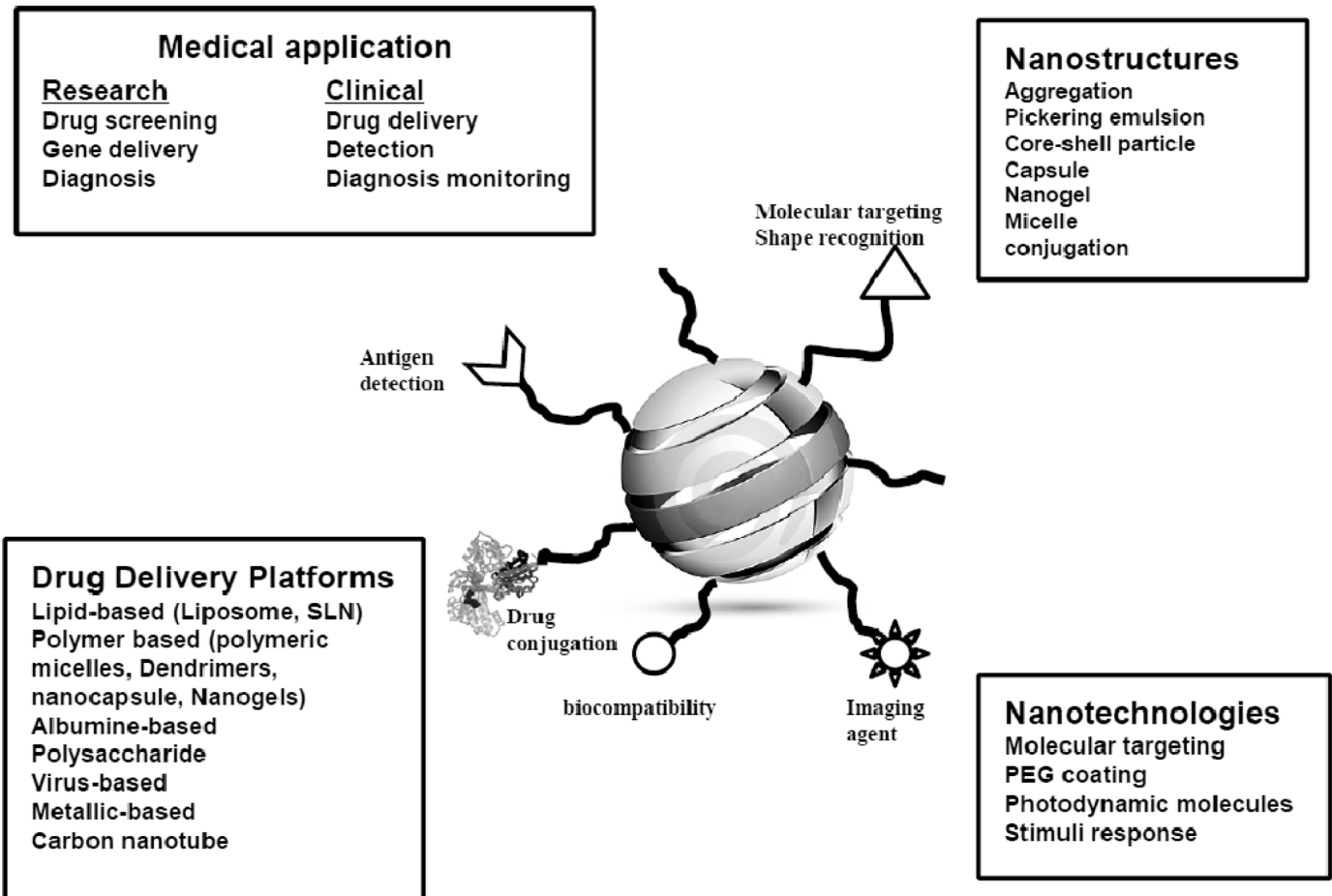

Figure 1. The multifunctional nanomedicine: application, structure, drug delivery platforms and nanotechnologies.

size of around $100 \mathrm{~nm}$, high stability in blood, high drug loading capacity, and low toxicity (Kataoka et al. 2001). Herein, poly(ethylene glycol) (PEG) was frequently chosen for the hydrophilic block as well as the component conjugating with protein/peptide drugs. The hydrophobic block has been tailormade corresponding to the physical/chemical properties required for controlled drug release (Oh et al. 2007a). The micelles formed by self-assembling amphiphilic block copolymers are 
Table II. Representative Chemical Structures of Functional Polymers for Nanomedicines

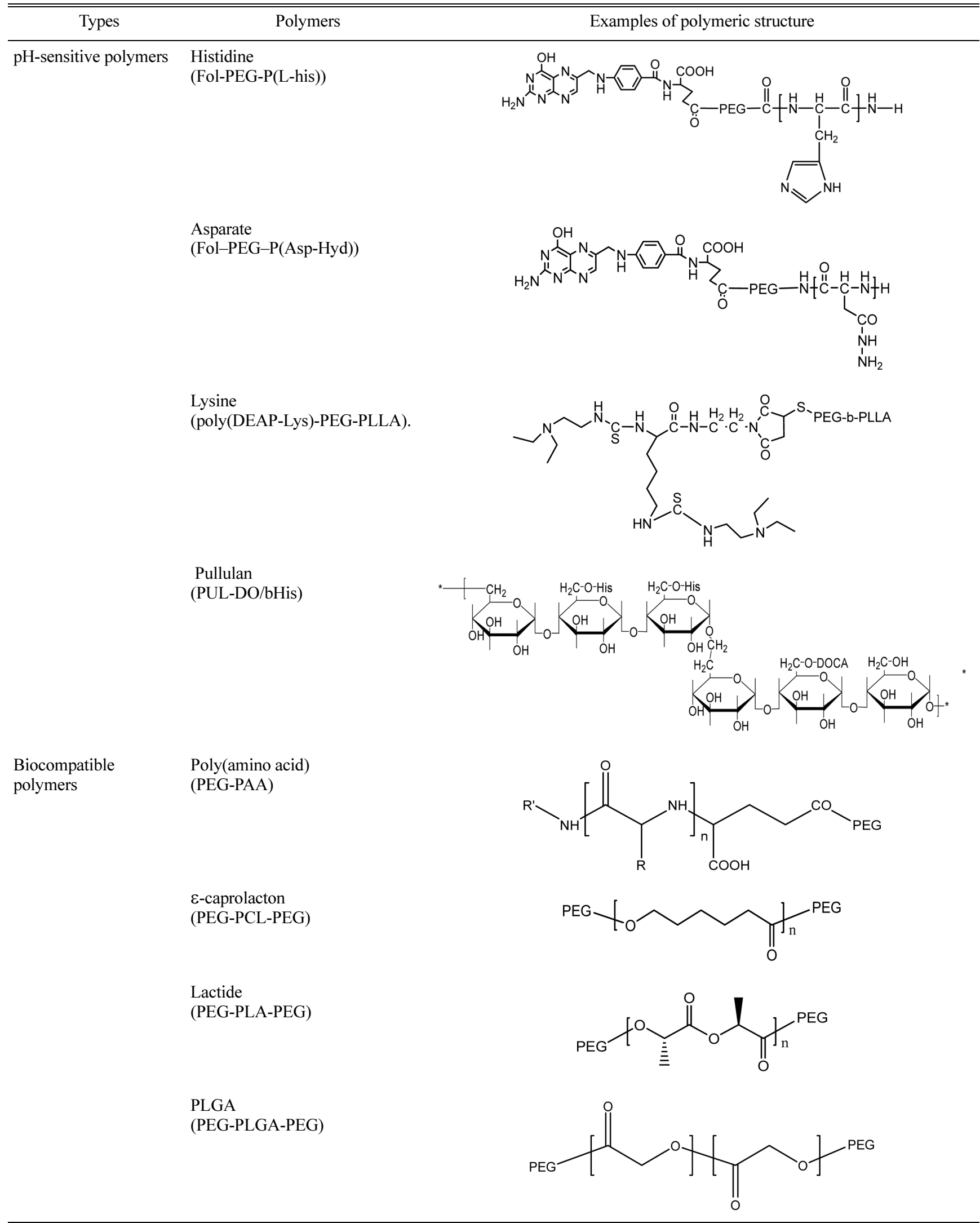


Table II. Continued

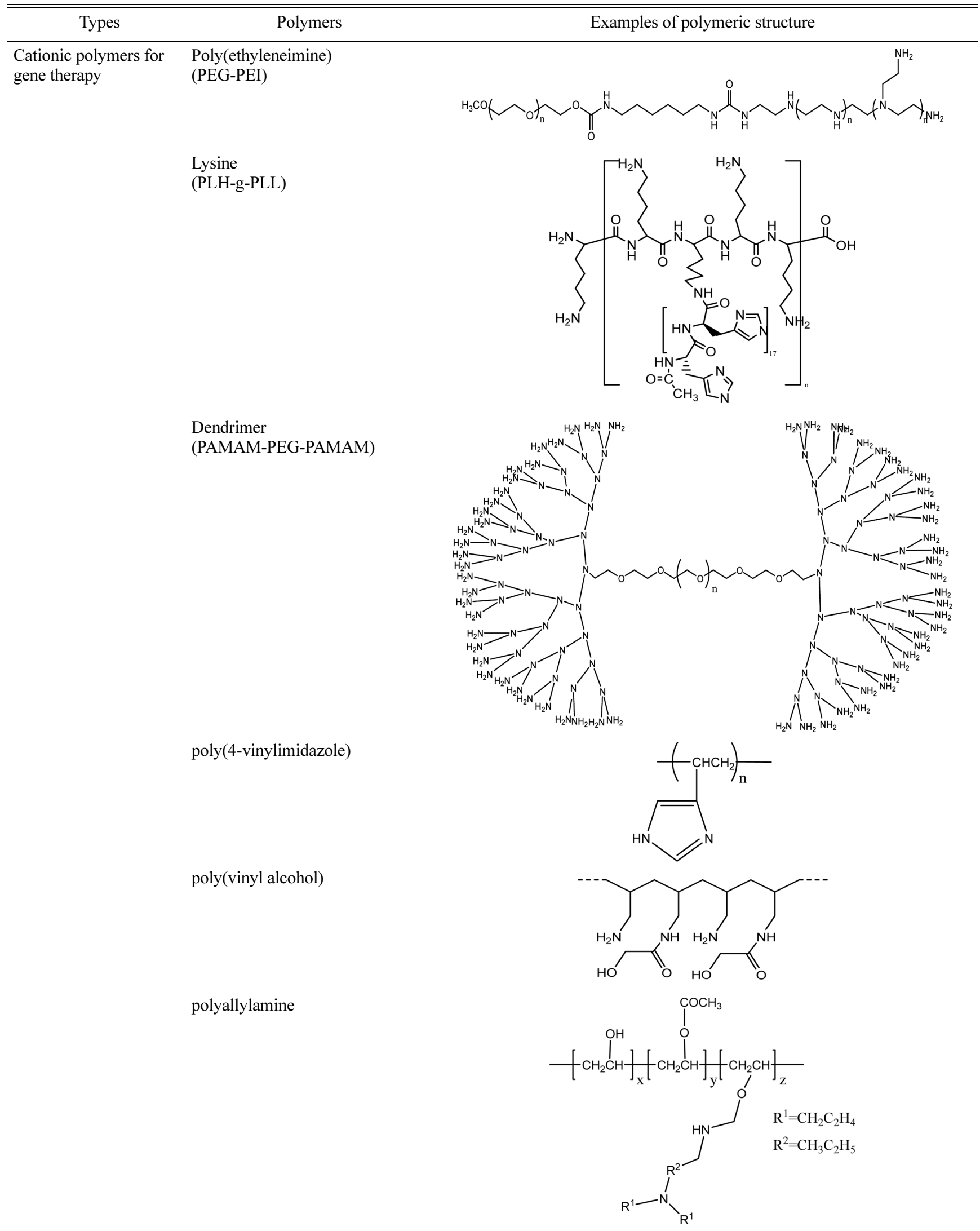


therefore suitable to avoid rapid the renal clearance and the reticuloendothelial system (RES)'s uptake due to the nano-size features and the reduced opsonization by steric hindrance of PEG, resulting in increasing circulation time of the drug carriers in the blood stream (Allen et al. 1999). In addition, the functionality of hydrophobic block enhances the pharmaceutical potential of drug carriers, providing advanced therapeutic activity in its target site and decreased non-specific drug accumulation in normal tissues (Kwon et al. 1995; Kwon et al. 1996). These nano-systems was evaluated and clinically tested particularly in the cancer research areas. The nano-systems with 50 200 nm size are accumulated in the area of tumor tissues by well-known enhanced permeability and retention (EPR) effect with the help of prolonged circulation time, and allow controlled drug release using several functional polymers such as stimuli-responsive polymers (particularly, $\mathrm{pH}$-sensitive polymers), biocompatible/ biodegradable polymers, and cationic polymers (Oh et al. 2007a; Oh et al. 2009a). The next chapters will address the examples of several polymers used for drug delivery system. The chemical structures of polymers present in Table II.

\section{pH-Sensitive Polymers}

Response to stimulus is a basic process of living systems. Therefore, stimuli-responsive smart polymeric materials in drug delivery have recently attracted great interest because of the broad opportunities for in vivo applications (Jeong et al. 2002; Schmaljohann 2006; Bawa et al. 2009; Liua et al. 2010; Stuart et al. 2010). Stimuli-sensitive polymers respond in a dramatic way to very slight changes in their environmental stimulus such as temperature, water, $\mathrm{pH}$, light, ionic strength, electric/magnetic field, and enzyme. These environmentally responsive polymers display the change in morphology, solubility (e.g., sol-gel transition), and surface properties of selfassemble drug carriers, giving rise to advent of novel drug delivery system (Oh et al. 2007a; Bawa et al. 2009; Stuart et al. 2010). Such nanosized systems could store and protect various drugs, and effectively deliver them inside cells by the environmental stimuli (Figure 2). In particular, $\mathrm{pH}$-sensitive polymers have been employed for this purpose (Schmaljohann 2006). Specifically, relating to cancer, more than $80 \%$ of the extracellular $\mathrm{pH}\left(\mathrm{pH}_{\mathrm{e}}\right)$ values in human and animal solid cancers are lower $\mathrm{pH}$ (6.5-7.2) than normal blood $\mathrm{pH}$ (7.4) due to anaerobic respiration and subsequent glycolysis (Tannock et al. 1989; Stubbs et al. 2000; Gillies et al. 2004). The polymers responding to $\mathrm{pH}_{\mathrm{e}}$ leads to triggered drug release at acidic cancer $\mathrm{pH}_{\mathrm{e}}$ (Oh et al. 2007a).

$\mathrm{pH}$-sensitive polymers are normally produced by adding pendant acidic or basic functional groups to the polymer backbone; these either accept or donate protons upon environmental pH (Langer et al. 2003). Ionizable polymers with a $\mathrm{pK}_{\mathrm{a}}$

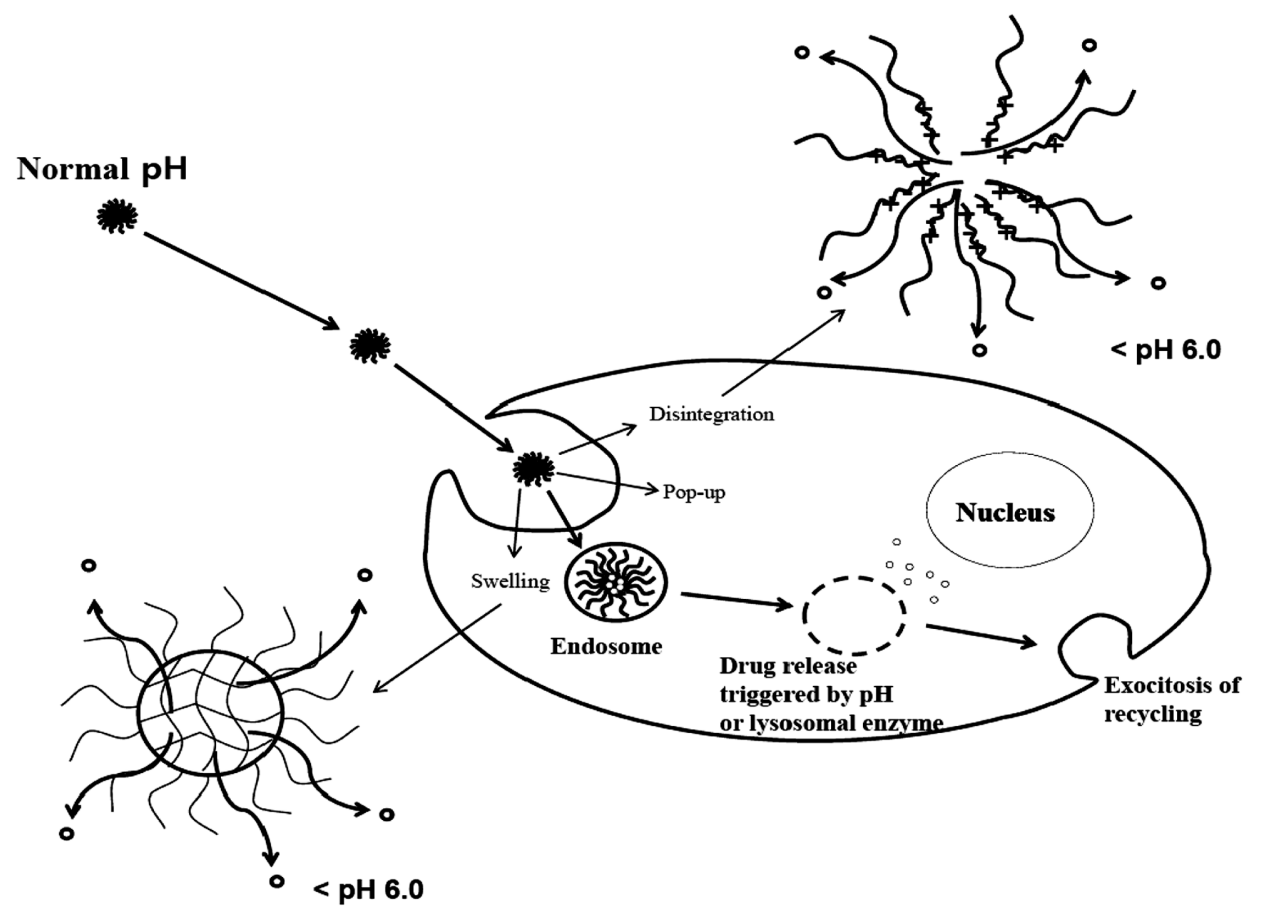

Figure 2. Schematic mechanism of $\mathrm{pH}$-sensitive carriers: The nanoparticles hold the drug inside the particle during blood circulation and trigger the drug release with $\mathrm{pH}$ change stimuli by swelling or disintegration. 
value between 3 and 10 are candidates as $\mathrm{pH}$-sensitive polymers. The change in the ionization state upon variation of the $\mathrm{pH}$ leads to a conformational change or a hydrophobic/ hydrophilic balance change. For example, the hydrogel prepared from $\mathrm{pH}$-sensitive polymers containing carboxylic acid groups show either sudden or gradual changes in their swelling behaviors as a result of changing the external $\mathrm{pH}$ (Lowman et al. 1999; Oh et al. 2007b). In the following section, several $\mathrm{pH}$-sensitive polymers will be discussed related to $\mathrm{pH}$ responsive systems.

\section{Polypeptide block copolymers}

Recently, polypeptide block copolymers have attracted attention as a means of producing nanovehicles because they are non-toxic, biocompatible, and biodegradable (Anderson et al. 1985; Gaucher et al. 2005a). The $\mathrm{pH}$-sensitive polypeptide includes poly(L-histidine) [poly(His)], poly(L-aspartic acid) [poly(Asp)], poly(L-lysine) [poly(Lys)], and their derivatives conjugated with polysaccharide (e.g., pullulan) (Table II).

Among polypeptides, poly(His) shows promise as a $\mathrm{pH}$-sensitive biomaterial for developing such delivery system, because its imidazole ring $\left(\mathrm{pK}_{\mathrm{b}} \sim 6.5\right)$ has lone pairs of electrons on the unsaturated nitrogen that convey $\mathrm{pH}$-dependent amphoteric properties to the molecule. Poly(His) ionizes below pH 7.0 and deionizes above $\mathrm{pH}$ 7.0, which makes it a tantalizing building block with which to develop a $\mathrm{pH}$-responsive micellar system (Lee et al. 2003b; Kim et al. 2005a; Lee et al. 2005b; Kim et al. 2008; Oh et al. 2008). Bae's group have reported poly(His) based $\mathrm{pH}$-sensitive micellar systems (Lee et al. 2003a; Lee et al. 2003b; Lee et al. 2005a). The micelles constructed from poly(His)(Mw 5,000)-b-PEG (Mw 2,000) copolymer showed different structures depending on $\mathrm{pH}$ due to protonation/deprotonation of imidazole rings of poly(His). Above the $\mathrm{pK}_{\mathrm{b}}\left(\mathrm{pK}_{\mathrm{b}} \sim \mathrm{pH}\right.$ 7.0), polyHis block became hydrophobic, resulting in formation of a stable micelle. Below the $\mathrm{pK}_{\mathrm{b}}$, the protonation of poly(His) made the copolymer more hydrophilic, resulting in destabilization of the micelles and triggering anticancer drug release (Lee et al. 2003b). In addition, the micelle mixed with poly(L-lactide) (PLA)-b-PEG responded endosomal acidic $\mathrm{pH}(<\mathrm{pH} 6.5)$ and showed high antitumor efficacy against MCF-7 cells in vitro and in vivo (Lee et al. 2003a).

Lee et al. have further developed the multifunctional $\mathrm{pH}$ responsive polymeric micelle system (denoted as PHSM $^{\text {pop-upTAT }}$ ) for treating various MDR phenotypes (Lee et al. 2005b; Lee et al. 2008b). The PHSM $^{\text {pop-upTAT }}$ is consisted of poly(His) (Mw $5 \mathrm{KDa}$ )- $b$-PEG (Mw $3.4 \mathrm{KDa}$ ) and PLLA (Mw $3 \mathrm{KDa}$ )- $b$-PEG (Mw $2 \mathrm{KDa}$ )-b-poly(His) (Mw $2 \mathrm{KDa}$ )-TAT peptide. Herein, short poly(His) (Mw $2 \mathrm{KDa}$ ) with TAT peptide is located to micellar core/shell interface at $\mathrm{pH}$ 7.4. As the $\mathrm{pH}$ of solution decreased from $\mathrm{pH} 7.4$ (normal $\mathrm{pH})$ to $6.8\left(\right.$ cancer $\mathrm{pH}_{\mathrm{e}}$ ), short poly(His) ionizes and allows pop-up of TAT peptide to the micellar shell surface, consequently leading to high accumulation of anticancer drugs in tumor cells with acidosis due to the extensive cellular internalized mechanism of TAT peptide expressed on the micellar surface (Lee et al., 2008b; Lewin et al. 2000).

In addition, Kim et al. have developed poly(L-histidine-coL-phenylalanine)- $b$-PEG diblock copolymers [poly(His-coPhe)-PEG] (Kim et al. 2005a). The $\mathrm{pK}_{\mathrm{b}}$ value of this diblock copolymer was controlled by adjusting the ratio of His/Phe in the poly(amino acid) block. The $\mathrm{pK}_{\mathrm{b}}$ of poly(His-co-Phe)-PEG ranges from $\mathrm{pH} 7.0$ to 6.0 . It is interesting to note that the micelles constituted with these block copolymers show different micelle behaviors (i.e., core/shell micelle strucutrue at $\mathrm{pH} 7.4$ and micellar disintegration below $\mathrm{pH}$ 6.7) at $\mathrm{pH}$ 6.07.0 , depending on the protonation/deprotonation of poly(Hisco-Phe). Recently, a refined work in Bae's group has shown that systems with different ratios of His/Phe resulted in triggered release of anticancer drugs below $\mathrm{pH}_{\mathrm{e}}$ (Kim et al. 2008).

Kataoka's group has designed micelles (size $\sim 65 \mathrm{~nm}$ ) formed using poly(Asp-g-hydrazone DOX)-b-PEG-folate (FA, as a tumor specific ligand) copolymers (Bae et al. 2003; Bae et al. 2005a; Bae et al. 2005b). The hydrazone bonds, in the polymer have most often been utilized to link polymers and drugs together to create smart drug delivery systems that respond to endosomal/lysosomal acidic pH (Bae et al. 2005a; Bae et al. 2005b; Hruby et al. 2005). The cleavage of such chemical bonds by acidic $\mathrm{pH}$ can accelerate antitumor drug release from nanovehicles. In vivo studies showed that these micelles were stable during blood circulation, providing minimal drug leakage and successfully accumulating in solid tumors through FA receptor-mediated endocytosis, followed by cytoplasmic DOX release via endosomal $\mathrm{pH}(\mathrm{pH}<6.5)$ induced cleavage of the hydrazone linkages.

$\mathrm{Oh}$ and Lee recently developed poly(Lys) based $\mathrm{pH}$-sensitive carriers (Oh et al. 2009b; Oh et al. 2009c). A micellar system (particle size: $\sim 165 \mathrm{~nm}$ ) constructed from poly $\left(\mathrm{N}^{\varepsilon}-(3-\right.$ diethylamino)propyl isothiocyanato-L-lysine) [poly(DEAP-Lys)]$b$-PEG- $b$-PLA], were designed to have a self-assembled flower-like arrangement consisting of two hydrophobic blocks [deprotonated poly(DEAP-Lys) block and PLA block] and a petal-like hydrophilic PEG block at physiological $\mathrm{pH}$ (Oh et al. $2009 \mathrm{c})$. As the $\mathrm{pH}$ decreases to slightly acidic $\mathrm{pH}(<\mathrm{pH} 7.0)$, the flower-like micelles undergo a change in the hydrophobicity of the micellar core. The protonation of poly(DEAP- 
Lys) changed the physical property of the polymer from hydrophobic to hydrophilic, resulting in disintegration of the micellar core. The systems using DOX as the model drug showed acceleration of DOX release from the micelles in response to tumor $\mathrm{pH}_{\mathrm{e}}(\mathrm{Oh}$ et al. 2009c). In addition, a surface chargeswitched polymeric micelle with a $\mathrm{pH}$ signal was developed as a drug-carrying nanovehicle for tumor targeting (Oh et al. 2009b). The micelles (particle size: $\sim 85 \mathrm{~nm}$ ), constructed from PLA- $b$-PEG- $b$-poly(L-lysine-N $\varepsilon$-(2,3-dimethyl maleic acid)) [poly(Lys)-DMA] and formed by self-assembly in an aqueous pH 7.4 solution, consisted of a hydrophobic core (PLA core) and two hydrophilic shells [PEG shell and Poly(Lys)-DMA shell] (Oh et al. 2009b). An anionic charge can be built on the surface of the micelle at a physiological $\mathrm{pH}(\sim \mathrm{pH} 7.4)$ due to 2,3-dimethyl maleic acid (DMA). However, DMA becomes chemically dissociated from the micelle under mild acidic conditions ( $\mathrm{pH}$ 6.5-7.0), resulting in the formation of a cationic surface due to the poly(Lys). This pH-triggered switch in surface charge may enhance cellular uptake of micelles to solid tumors, via an adsorptive endocytotic pathway due to the electrostatic interaction between micelles and cells. In addition, blending of the poly(His) into the hydrophobic core provides a mechanism for endosomal $\mathrm{pH}$-triggered drug-release from the polymeric micelle (Oh et al. 2009b).

Recently, our group developed a imidazole containing $\mathrm{pH}$ sensitive polymer with the structure of a poly(L-aspartic acid$g$-imidazole)- $b$-poly(ethylene glycol) [poly(Asp- $g$-Im)-PEG] block copolymer. The prepared poly(Asp- $g$-Im)- $b$-PEG is zwitterionic with a pI $6.5 ; 60 \%$ of the available carboxyl groups of poly(Asp- $g$-Im)- $b$-PEG were substituted by imidazole groups. The micelles prepared from poly(Asp- $g$-Im)- $b$ PEG showed $\mathrm{pH}$ dependent physical properties in critical micelle concentrations (CMC), particle sizes, zeta potentials, and morphologies (unpublished data).

\section{pH-sensitive polymeric network}

$\mathrm{pH}$-sensitive micelles confer disruption and aggregation as changed $\mathrm{pHs}$ while $\mathrm{pH}$-sensitive network (hydrogel) showed swelling/de-swelling depending on change of $\mathrm{pH}$ (Figure 3). These nano-sized networks (nanogel) can be prepared by shell cross-linking (SCL) or core cross-linking (CCL) with the $\mathrm{pH}$ sensitive block copolymers mentioned above. A variety of chemical cross-linking methods including carbodiimide-mediated cross-linking, quaternization of amino groups, and "click" chemistry for polymer networks have been developed (Yusa et al. 2009).

Lee et al. developed a novel virus-like nanogel (virogel) system utilized from poly(His-co-Phe)-PEG for treatment of wild and MDR tumor cells (Lee et al. 2008c). This system consists of a lipophilic core poly(His-co-Phe) and two hydrophilic shells with PEG and bovine serum albumin (BSA). One end of the PEG is linked to the core-forming block and the other is randomly linked to BSA, which forms a capsid-like shell (Lee et al. 2008a); this structure is formed by an Oil-in-water emulsion method. It is worth noting that this system has a reversible swelling/deswelling property and different anticancer drug release profiles depending on $\mathrm{pH}$.

Nagasaki group prepared a $\mathrm{pH}$-sentive PEGylation nanogel via emulsion copolymerization of 2-(N,N-diethylamino)ethyl methacrylate (EAMA) with heterobifunctional PEG bearing a 4-vinylbenzyl group and carboxyl group using ethylene glycol dimethacrylate as cross-linker (Oishi et al. 2007). These nanogels showed a limited drug release from nanogel under physiological conditions. In acidic endosome after internalized by cells through receptor-mediated endocytosis, the nanoparticles swelled and released drug sequestered in the particle core.

Hayashi et al. prepared a nanogel composed of bi-functional PEG with vinylbenzyl group and carboxylic acid group and 2(diethylamino)ethyl methacrylate (PEAMA) as a crosslinker (Hayashi et al. 2004). The prepared nanogel showed $\mathrm{pH}$ dependent swelling/deswelling behavior due to the amino groups in the PEAMA $\left(\mathrm{pK}_{\mathrm{a}}=7.5\right)$ core. The size of nanogel was ca. $60 \mathrm{~nm}$ in neutral to alkaline region and sharply increased to $140 \mathrm{~nm}$ by decreasing the $\mathrm{pH}$ to 6 . This nanogel can be used for diagnostics and controlled drug releasing devices and furthermore, the carboxylic acid on the surface of
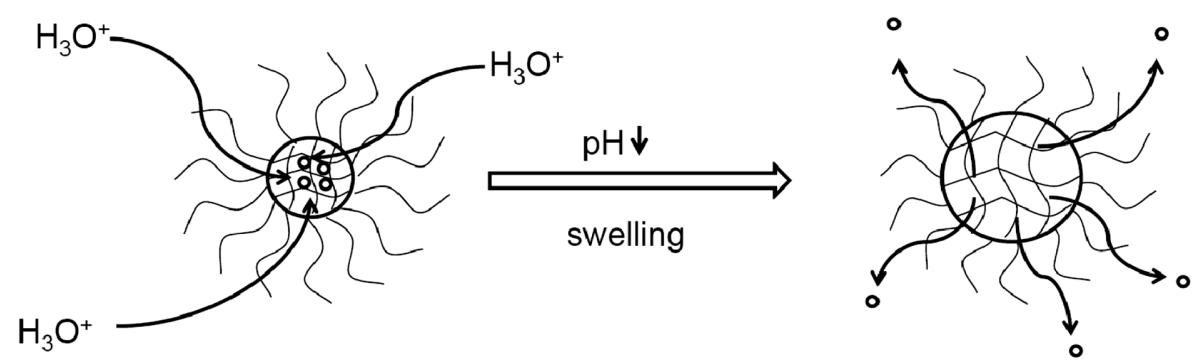

Figure 3. Schematic swelling mechanism of nanogels by decrease of $\mathrm{pH}$ : The polymer with protonated amine groups by decrease of $\mathrm{pH}$ start to swell, resulting in drug release. 
nanogel can be available as conjugation site of various ligands.

Natural carbohydrate-based biopolymers such as chitosan, dextran, and hyaluronan are also utilized for nanogel fabrication (Khandare et al. 2006). In particular, chitosan is the second abundant polysaccharide and a cationic polyelectrolyte present in nature and has shown favorable biocompatibility characteristics as well as the ability to increase membrane permeability, both in vitro and in vivo (Ravi Kumar 2000; Domard et al. 2002; VandeVord et al. 2002; Kumar et al. 2004). In addition, chemical modification of chitosan leads to various derivatives with improved properties, which are utilized for development of various $\mathrm{pH}$-sensitive hydrogel (Kumar et al. 2004). For example, Lee's group reported a self-organized 3diethylaminopropyl (DEAP)-bearing glycol chitosan nanogel (Oh et al. 2010). The novel pH-responsive nanogel composed of glycol chitosan (GCS) grafted with functional 3-diethylaminopropyl (DEAP) groups was designed to have a selfassembled arrangement consisting of hydrophilic block (GCS) and hydrophobic block (DEAP) at physiological pH. As the $\mathrm{pH}$ decreased to 6.5-7.0 (tumor extracellular $\mathrm{pH}$ ), the nanogel was destabilized due to the protonation of DEAP. Drug, DOX loading nanogels showed accelerated drug release and increased drug uptake by lung carcinoma A549 under a slightly acidic $\mathrm{pH}$. In addition, Yu et al. have suggested a pHsensitive nanogel prepared by electrostatic attractions between chitosan and ovalbumin (Yu et al. 2006). The nanogels did not dissociate in the $\mathrm{pH}$ range of 2-10.5. However, the size of nanogels was $\mathrm{pH}$-dependent and smaller size at $\mathrm{pH} 5.4$ due to the protonation of chitosan and stabilization by electrostatic interaction with ovalbumin.

$\mathrm{Na}$ et al. utilized oligomeric sulfadimethoxine (OSDM) to prepare $\mathrm{pH}$-sensitive nanosized hydrogels ( $\mathrm{Na}$ et al. 2003; $\mathrm{Na}$ et al. 2004). Modified hydrophobic pullulan acetate (PA) was coupled with OSDM using ester linkages (Table II). At physiological $\mathrm{pH}$ in aqueous conditions, nanoparticles with average diameters 50-60 nm exist in emulsion. However, as $\mathrm{pH}$ decreased from 7.2 to 6.8 , the nanoparticles shrank, aggregated, and enhanced drug release rates due to the rapid interior restructuring of the nanoparticles in this $\mathrm{pH}$ range. In addition, the amount of DOX released from the nanoparticles at $\mathrm{pH} 6.8$ and 6.2 was significantly higher than the amounts released at pH 8.0 and 7.4 in 24 hours. In vitro, this system also showed enhanced cell cytotoxicity against human breast adenocarcinoma cells (MCF-7) at pH 6.8 compared to relatively low cytotoxicity at $\mathrm{pH}$ 7.4. Recently, they have studied another self-organized nanogels composed of hydrophobized pullulan (PUL)-No-Boc-L-histidine (bHis) conjugates, which responded to tumor $\mathrm{pH}_{\mathrm{e}}(\mathrm{Na}$ et al. 2007). The size and critical aggregation concentration of nanogel was drastically increased as decrease of $\mathrm{pH}$ to below 7.0 compared to those in physiological condition. The drug release profile and cytotoxicity of DOXloading nanogel was similar to previous works.

\section{Biocompatible and Biodegradable Polymers}

Over the past decade, there has been considerable interest in developing biocompatible/biodegradable drug delivery systems involving in a combination of nanotechnology and polymer chemistry. Most of the polymers used for nanoparticles should be biocompatible and/or biodegradable (or bioerodible), and be thus subject to approval by the Food and Drug Administration (FDA) (Duncan 2003; Brannon-Peppas et al. 2004; Kim et al. 2005b). Several biocompatible polymers including poly(amino acid), poly(L-lactide) (PLA), poly(L-glyolide) (PGA) and poly(lactide-co-glycolide) (PLGA) were developed for nanosized drug delivery systems (Table II).

Knowing the fact that effectiveness of nano-delivery systems to improve the stability and absorption depends strongly on their polymer composition; physicochemical properties of polymer can be altered by conjugating with polyethylene glycol (PEG), a hydrophilic biocompatible polymer. Many biodegradable amphiphilic block copolymers based on poly(amino acid) and aliphatic polyesters (e.g. poly(Asp)- $b$-PEG, PLA- $b$ PEG, PLGA- $b$-PEG, and PCL- $b$-PEG), have been synthesized and frequently applied in DDS due to their safety prole (Gref et al. 1994; Mosqueira et al. 2001; Ge et al. 2002). The drug is typically either dispersed within the polymeric nanoparticle, (a)

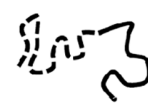
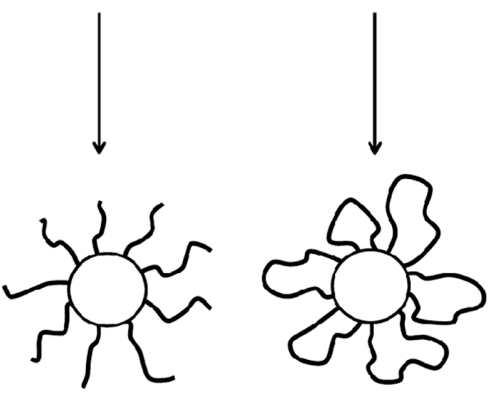

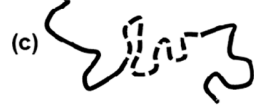

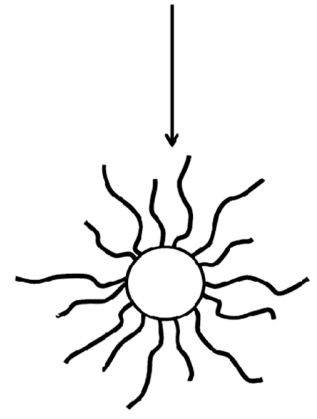

Hydrophobic polymer (PLA, PLGA, PCL, etc.) Hydrophilic polymer ( $P E G$, etc.)

Figure 4. Structure of nano-sized polymeric micelles formed by amphiphilic triblock copolymers in aqueous solution(A: hydrophilic, B: hydrophobic): (a) AB type of diblock copolymer form a conventional micelle; (b) BAB type of triblock copolymers form a flower-like micelle; (c) ABA type of triblcok copolymer form more hydrophilic micelle. 
micelle or conjugated to the polymeric back-bone (Park et al. 2008). In particular, polymeric micelles prepared from amphiphilic block copolymers introduced by Ringsdorf in 1984 (Bader et al. 1984) have intensive investigated for hydrophobic drug carriers. The biamphiphilic block copolymers with various compositions such as di, tri, multi-block copolymers or grafted copolymers, was designed for the pharmaceutical applications (Gaucher et al. 2005b). The representative micellization of various block copolymers was proposed in Figure 4. Some polymeric micelles possess excellent biocompatibility and biodegradability, and can provide various bio-functionalities. In addition, they prolong the plasma half-life and improve the bioavailability of drugs. Various combinations of functional polymers and biomolecules can be generated, allowing the properties of polymeric micelles to be tailored for different biomedical applications.

\section{poly(amino acid) based systems}

PEG is a biocompatible water-soluble polymer, which is widely used in the biopharmaceutical industry because of its excellent water solubility, chain mobility, and non-immunogenicity. PEG is non-toxic and can be cleared from the body through renal ltration with a molecular weight of less than 30 KDa (Yamaoka et al. 1994). When it comes to poly(amino acid), it is also highly biocompatible, non-toxic, and economic with versatile functional groups such as hydroxyl, carboxyl, amino, and thiol groups. Such a variety of functional groups is of great benet to modify the chemical structure of the core for drug conjugation. The poly(amino acid)s including poly(Asp), poly(Lys), and poly(His) are biodegradable, biocompatible and relatively nontoxic. In biological fluids, they undergo hydrolysis and/or enzymatic degradation to yield biocompatible Lamino acid materials (Yokoyama et al. 1998). These block copolymers can be used for a $\mathrm{pH}$-sensitive micellar systems, drug conjugated system, polyionic complexes, and nanogels introduced in previous section.

\section{Polyester based systems}

Poly(esters) are the best characterized and most widely studied biodegradable system. The synthesis of poly(esters) has received attention as much as the degradation of these materials. Poly(esters) have been extensively employed in drug delivery applications and comprehensively reviewed. The biocompatible polyesters have been widely used for drug delivery, because they are gradually degraded in the body and thus do not require an additional removal procedure after implantation (Kissel et al. 2002). The representative polyesters that can be used as the hydrophobic segments of the copol- (a)

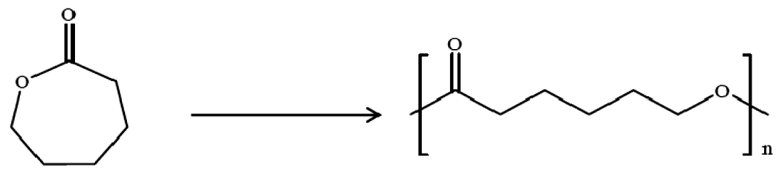

(b)

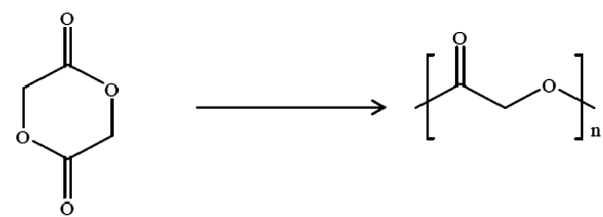

(c)

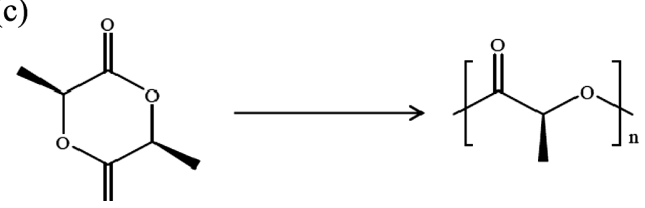

Figure 5. Synthetic schemes of poly(ester) by ring opening polymerization with cyclic lactones: (a) poly(caprolactone); (b) poly(glycolic acid); (c) poly(lactic acid)

ymers include PGA, poly( $\varepsilon$-caprolactone) (PCL), as well as copolymers of lactide/glycolide (Kissel et al. 2002; Forrest et al. 2006; Lin et al. 2006). The more prominent poly(esters) and their starting monomers are shown in Figure 5.

PLA-PEG block copolymers have been studied for their potential as controlled and targeted drug delivery systems of anticancer drugs, proteins, oligonucleotide, and DNA (Avgoustakis et al. 2003). Even though the high molecular weight of PLA block resulted in significantly less stability in aqueous dispersions, by adjusting the ratio of PLA/PEG block, the physicochemical properties can be improved such as the small size of micelles $(50 \sim 100 \mathrm{~nm})$, low critical micelle concentration, long blood circulation time, and high drug loading capacity (Kissel et al. 2002). PEG-b-PLA has been evaluated as a carrier for paclitaxel (Burt et al. 1999), and copolymer was found to encapsulate as much as $25 \%$ of the loading content of the drug. The micellar formulation of paclitaxel produced a 5-fold increase in the maximum tolerated dose as compared with Cremophor-formulated paclitaxel. Recently, Jain et al. developed a PLA-based nanoparticles formulated using different block copolymers $\mathrm{AB}, \mathrm{ABA}$ and $\mathrm{BAB}$ (where ' $\mathrm{A}$ ' is PLA and ' $\mathrm{B}$ ' is PEG, Figure 6) encapsulating hepatitis $B$ surface antigen to evaluate their efficacy as oral vaccine delivery system (Jain et al. 2010). The results of in vitro studies engrave the efficiency of copolymeric nanoparticles to retain encapsulated antigen and average particle size even after $2 \mathrm{~h}$ incubation in simulated gastric fluid and simulated intestinal fluid. In addition, in vitro and in vivo studies demonstrate that BAB nanoparticles depict enhanced 
(a) PLA-PEG Diblock copolymer (AB)<smiles>COC(C)(C)CCCOC(C)(C)C(C)(C)C(=O)C(C)OC(C)C</smiles>

(b) PLA-PEG-PLA Triblock copolymer (ABA)

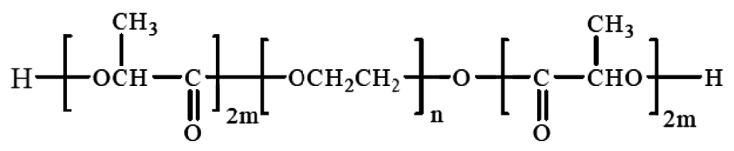

(c) PEG-PLA-PEG Triblock copolymer (BAB)

$$
\left.\left.\mathrm{H}_{3} \mathrm{C}-\mathrm{O}-\mathrm{CH}_{2} \cdot \mathrm{CH}_{2}\right]_{\mathrm{n}} \stackrel{\mathrm{O}}{\mathrm{C}}\left[\begin{array}{l}
\mathrm{CH}_{3} \\
\mathrm{CHO}-\mathrm{C}
\end{array}\right]_{\mathrm{O}}\right]_{2 \mathrm{~m}}\left[\mathrm{O}-\mathrm{CH}_{2}-\mathrm{CH}_{2}\right]_{\mathrm{n}}^{\mathrm{CH}_{3} \mathrm{O}}
$$

Figure 6. Structure of (a) AB diblock; (b) ABA and (c) BAB triblock copolymers with PLA and PEG.

mucosal uptake leading to effective immune response as compared to other copolymeric nanoparticles.

The PEG- $b$-PLGA has shown prolonged residence in blood, compared to conventional PLGA nanoparticles without the PEG chain (Avgoustakis et al. 2003). The related triblock copolymer-based PEG- $b$-PLGA- $b$-PEG is known to form biodegradable, temperature responsive micelles (Jeong et al. 2000) that may be administered as a solution only to become a sustained release-mediating gel at body temperature.

PCL approved by the FDA is hydrophobic and biodegrable. PEG- $b$-PCL is semicrystalline, with a controlled degree of crystallinity by altering the ratio of PEO to PCL. Indomethacine, a NSAID and rapamycin, an antibiotics, were

(a) Dextran

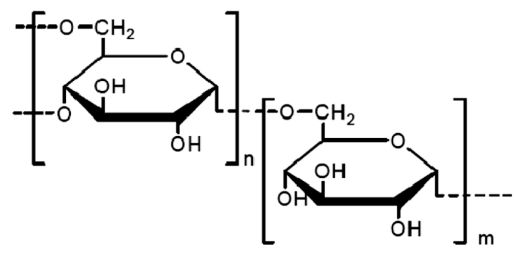

(c) Pullulan

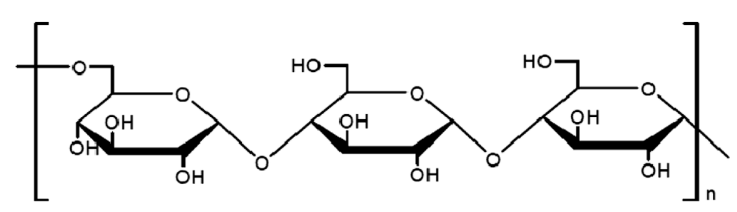

effectively solubilized by the micelles and exhibited sustained release in vitro and in vivo (Kim et al. 1998; Shin et al. 1998; Forrest et al. 2006). Zhang et al. developed novel ABA-type amphiphilic triblock copolymer composed of PEG- $b$-PCL- $b$ PEG. The triblock copolymers have been assembled into micellar structures capable of encapsulating the water-insoluble anticancer drug. The drug release rate could be precisely controlled by adjusting the copolymer composition to control the hydrophilicity lipophilicity balance (Zhang et al. 2005). Ge et al. synthesized PCL- $b$-PEG- $b$-PCL triblock copolymer for hydrophobic drug carriers (Ge et al. 2002). The PEG/PCL ratio of copolymer intensively affected the micelle size, drugloading content, and drug release. The increase of PCL resulted in increase of size and drug content and decrease of drug release. Recently, a new type of highly stable polymer micelle formed of core-surface-crosslinked nanoparticles (SCNP) made from PEG or poly[2-(N,N-dimethylamino)ethyl methacrylate] (PDMA) as hydrophilic components and PCL as hydrophobic chains has been evaluated as a carrier for cisplatin (Xu et al. 2006). The positive charge of nanoparticles due to PDMA induced a facilitated cell internalization and thus high anticancer drug efficacy.

\section{Polysaccharides based systems}

Self-assembled nanoparticles comprised of hydrophobically modified polysaccharides were also studied as drug carriers due to their excellent biocompatibility and easy preparation. A number of polysaccharides have been investigated in terms of creating self-assembling systems, including dextran (Kim et al. 2000), glycol chitosan (Son et al. 2003), pullulan ( $\mathrm{Na}$ et al. 2004), curdlan (Na et al. 2000), and heparin (Park et al. 2006a) (Figure 7). These polysaccharides are natural, water-soluble polymers that are inherently biocompatible and biodegradable.

(b) Glycol chitosan

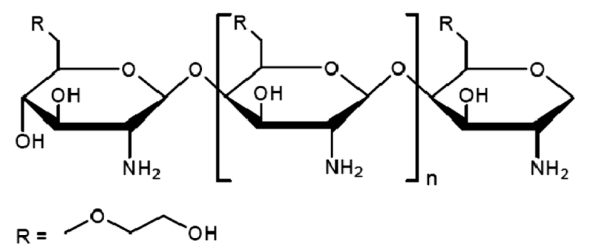

(d) Curdlan

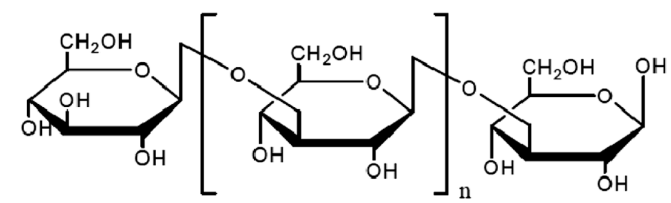

Figure 7. Polysaccharides used in nanomedicines 
Polysaccharide-based nanoparticles are prepared mainly by covalent crosslinking, ionic crosslinking, polyelectrolyte complexation, and self-assembly of hydrophobically modified polysaccharides (Liu et al. 2008). The core-shell structure of self-assembled hydrogels is considered a potential system for effective delivery of hydrophobic drugs.

\section{Polycations for Genes}

The success of gene therapy depends on two essential components; an effective therapeutic gene and a safe and efficient delivery system (Park et al. 2006b; Park et al. 2008). The gene carriers can deliver the therapeutic genes to the specific tissue or organ without delivery to normal tissues. Two different types of carriers, viral and non-viral vectors, have been examined for use in delivering genes to the target site. Even though viral vectors exhibit better transfection properties, both in vitro and in vivo, a large number of problems by using these vectors such as the induction of an immune response against the viral proteins, lack of specificity toward target cells, possible recombination with wild-type viruses, limitations in the size of inserted gene, and difficult large-scale pharmaceutical grade production occur. (Lehrman 1999; Gore 2003; Liu et al. 2003; Sun et al. 2003; Jeong et al. 2007). As a result, non-viral vector mediated systems have become of interest because of much safer, more cost-effective, and easier to manufacture than viral vector systems. Non-viral gene delivery systems generally consist of three categories: (i) naked DNA delivery, (ii) lipidbased, and (iii) polymer-based delivery. In this paper, the different synthetic polymers used as a non-viral delivery carrier are discussed hereunder.

\section{Polyethyleneimine (PEI)}

Most polymer-based non-viral vectors are cationic in nature and can interact electrostatically with negatively charged gene (DNA, siRNA), resulting in nanosized ionic complexes called as polyplex (Figure 8(a)). These polyplexes condensed can protect the DNA from degradation and the positively charged particles generated by the presence of more cationic polymers than genes (DNA, siRNA) facilitate uptake into the cell due to electrostatic interactions with anionic cell surface, and subsequently mediating endocytosis. Once localized inside the cells, the polyplexes should escape from the endosomal compartment, move to a proximal position of the nucleus, and unload the nucleic acid drug to be transported within the nucleus (Brown et al. 2001; Lee et al. 2002; Lechardeur et al. 2005). (Figure 8(b))

Among the non-viral gene carriers, polyethyleneimine (PEI)

(a)

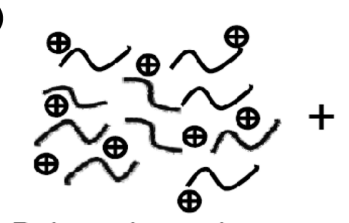

Polymeric carrier

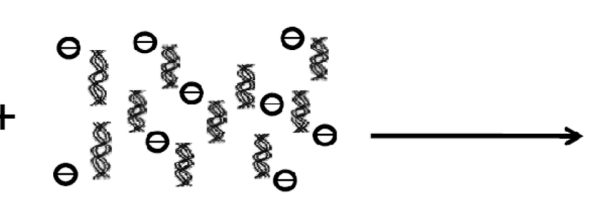

gene(DNA, siRNA)
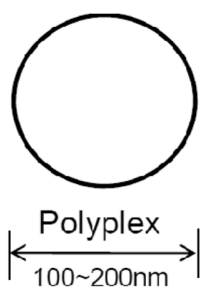

(b)
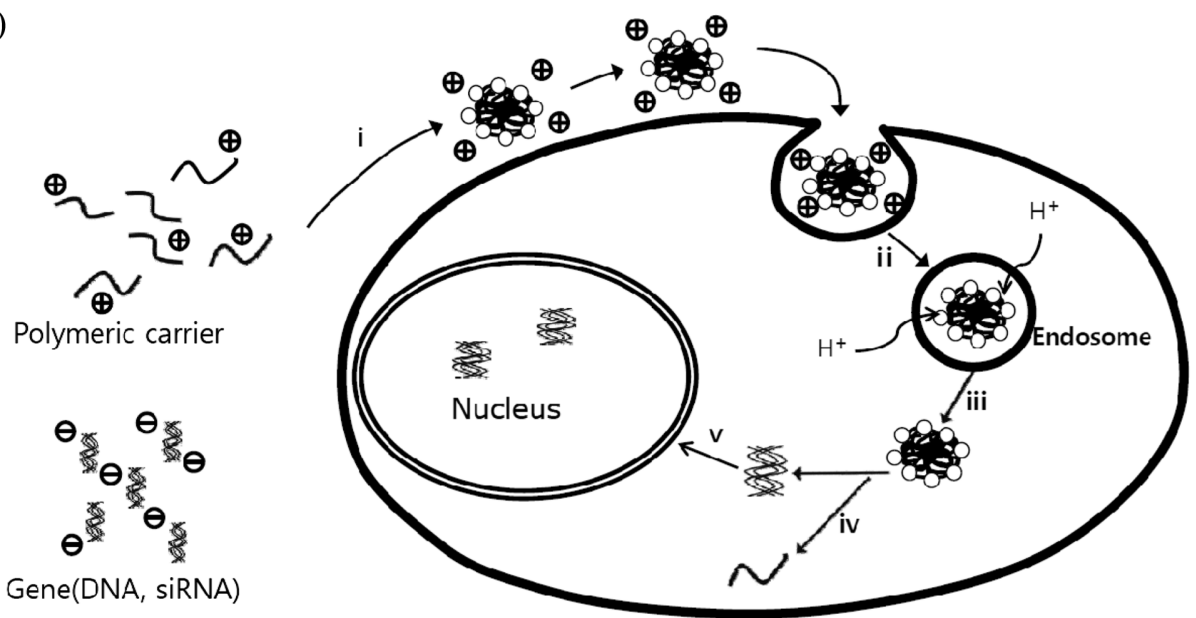

Figure 8. Schematic illustration of (a) the formation of polyplexes by ionic interaction between negatively charged DNA and polycations, (b) Barriers to gene delivery-Design requirements for gene delivery systems include the ability to (i) package therapeutic genes; (ii) gain entry into cells; (iii) escape the endosomal pathway; (iv) effect DNA/vector release; (v) traffic through the cytoplasm and into the nucleus. 
has been known as the most effective non-viral vector because of favorable properties with respect to gene protection, transfection efficiency, endosomal escape, and release from the carrier (Zhang et al. 2004). PEI of high molecular weight contributes to the formation of highly condensed particles and efficient delivery of DNA. However, a high molecular weight PEI confer significant cytotoxicity and its long-term safety problems due to nonbiodegradability (Kircheis et al. 2001). Thus, various strategies have been attempted to increase the transfection efficiency of PEI-based gene carrier and to decrease its cytotoxicity.

Petersen et al. presented that PEI-grafted PEG (PEI-g-PEG) with different degree of grafting ratios with PEG (550 Da, $5 \mathrm{KDa}$, and $20 \mathrm{KDa}$ ) was synthesized to address blood compatibility, cytotoxicity, and transfection activity (Petersen et al. 2002). Cell cytotoxicity of PEI- $g$-PEG was greatly reduced if $\mathrm{MW}$ was more than $5 \mathrm{KDa}$, while the transfection efficiency of PEI- $g$-PEG was still comparable to that of PEI. The surface charge of PEI- $g$-PEG/DNA complexes reduced when PEG molecular weight was more than $5 \mathrm{kDa}$, due to the charge shielding effect of PEG. However, a PEI- $g$-PEG conjugate with a low molecular weight PEG (Mw $550 \mathrm{Da}) \mathrm{did}$ not show the charge shielding effect. Cytotoxicity was independent on molecular weight of PEG but affected by the degree of PEG substitution.

\section{Poly( L-lysine)}

Poly(Lys) as a linear polypeptide is biodegradable. The repeated lysine residues with primary e-amino acid are protonated in the physiological environment and condensed with negative DNA by electrostatic interaction. However, poly(Lys) showed high toxicities, unstable polyplex, and poor transfection ability (Farrell et al. 2007).. The relatively low transfection level of poly(Lys) is possibly due to sequestering into endosomes or the inefficient release of DNA from the complexes (Midoux et al. 1999). To address these problems of poly(Lys), the backbone of poly(Lys) was modified with histidine of imidazole derivatives to provide the endosome escape property.

Midoux et al. presented histidylated Poly(Lys)/plasmid DNA (pDNA) to increase the transfection efficiencies (Midoux et al. 1999). Histidine derivatives were conjugated to å-amino groups of poly(Lys) and the hystidylated Poly(Lys) formed a polyplex with pDNA. The resulting polyplexes owned a buffering capacity at endosomal $\mathrm{pH}$, resulting in membrane destabilization and allowing the polyplexes to escape from the endosome. Benns et al. demonstrated that poly(His) grafted poly(Lys) enhanced the transfection efficiency by 2.5 -fold compared to unmodified poly(Lys) at a DNA/polymer weight ratio of 1:20 (Benns et al. 2000).

\section{Polyamidoamine dendrimers}

Dendrimers such as polyamidoamine (PAMAM) have also been studied for their high transfection efficiency of gene delivery in vitro and in vivo (Dufes et al. 2005). The toxicity of dendrimers is of major concern for their medical use. In general, in vivo toxicity of dendrimers is related with various factors such as the chemical structure, surface charge, generation, and dose of dendrimers (Aillon et al. 2009). Jevprasesphant et al. reported that surface modification with PEG or replacement with low generation dendrimers was able to improve the biocompatibility of these biomaterials (Jevprasesphant et al. 2003). A PAMAM- $b$-PEG- $b$-PAMAM based tri-block copolymers were also reported as carrier for gene delivery (Kim et al. 2004). To overcome the drawbacks of PAMAM dendrimers such as low water solubility and considerable cytotoxicity, the introduction of PEG to engineer a nontoxic and highly transfection efficient polymeric gene carrier was developed. The copolymer composed of a PEG core and two PAMAM substructures on both sides formed a selfassembled polyplex with pDNA, enhancing water solubility compared to the PAMAM dendrimer itself. The copolymer had little cytotoxicity in mammalian cells, low interaction with serum, and high transfection efficiency comparable to that of PEI in vitro.

\section{Other polymers}

Various other synthetic polymer vectors are currently being tested for gene delivery research including poly(4-vinylimidazole) (Ihm et al. 2003), poly(vinyl alcohol) (Wittmar et al. 2005), polyallylamine derivatives (Boussif et al. 1999), etc. These polymers showed promising properties for gene delivery (Table II).

Poly(4-vinylimidazole) as gene carrier showed high transfection efficiency compared to that of PEI through the proton sponge mechanism of imidazole groups and low cell toxicity (Ihm et al. 2003). Kissel's group presented the biophysical and transfection studies of an amine modified poly(vinyl alcohol) for gene delivery (Wittmar et al. 2005). Significant differences in physicochemical properties of the polyplex with DNA were observed by changing both the degrees of amine substitution and the structure of the PVA backbone, demonstrating that both electrostatic and hydrophobic interactions affected DNA condensation. These studies suggested an influence of the polycation structure on the morphology of condensed DNA in polyplexes. Boussif et al. evaluated polyallylamine derivatives 
for gene delivery and found that their ability to mediate gene transfer into cells increased by several orders of magnitude (Boussif et al. 1999). Transfection efficiency was found to be dependent on the substitution level of amino groups and reached highest levels in the presence of lysosomotropic and/ or fusogenic agents.

\section{Conclusions}

Polymeric based nanomedicines are a very interesting area of research in the future. In particular, nanomedicines for cancer treatment will be a promising modality to overcome the reluctant disease. This article is briefly discussed on the polymers for nanomedicine including $\mathrm{pH}$-sensitive polymers, biocompatible/biodegrdable polymers, and polycations for gene carriers. Smart polymers have emerged with great potential and enabled the development of various drug delivery systems that are biologically inspired. Various polymers with the favorable properties such as environmental stimuli response, biocompatibility, biodegradability, targetable modification, and cationic polymers for gene carriers can provide significant advantages to innovating drug delivery systems. The advances in nanotechnology, polymer chemistry, and drug delivery systems should produce numerous polymeric nanomedicines that can contribute to human health.

\section{Acknowledge}

This work was supported by the National Research Foundation of Korea (NRF) grant funded by the Korea government (MEST) (no. 2009-0065831 and no. 2009-0072394) and a grant of the Korean Health Technology R\&D Project, Ministry for Health, Welfare \& Family Affairs, Republic of Korea. (A092018)

\section{References}

Aillon, K.L., Xie, Y., El-Gendy, N., Berkland, C.J. and Forrest, M.L., 2009. Effects of nanomaterial physicochemical properties on in vivo toxicity. Adv Drug Deliv Rev 61(6), 457-66.

Allen, C., Maysinger, D. and Eisenberg, A., 1999. Nano-engineering block copolymer aggregates for drug delivery. Colloids and Surfaces B: Biointerfaces 16(1-4), 3-27.

Anderson, J.M., Spilizewski, K.L. and Hiltner, A., 1985. Poly-áamino acids as biomedical polymers. In: Biocompatibility of Tissue Analogs.

D. F. Williams. CRC Press, Boca Raton.

Avgoustakis, K., Beletsi, A., Panagi, Z., Klepetsanis, P., Livaniou, E., Evangelatos, G. and Ithakissios, D.S., 2003. Effect of copolymer composition on the physicochemical characteristics, in vitro stability, and biodistribution of PLGA-mPEG nanoparticles. International Journal of Pharmaceutics 259(1-2), 115-127.

Bader, H., Ringsdorf, H. and Schmidt, B., 1984. Watersoluble polymers in medicine. Die Angewandte Makromolekulare Chemie 123(1), 457-485.

Bae, Y., Fukushima, S., Harada, A. and Kataoka, K., 2003. Design of environment-sensitive supramolecular assemblies for intracellular drug delivery: polymeric micelles that are responsive to intracellular pH change. Angew Chem Int Ed Engl 42(38), 4640-3.

Bae, Y., Jang, W.D., Nishiyama, N., Fukushima, S. and Kataoka, K., 2005a. Multifunctional polymeric micelles with folatemediated cancer cell targeting and $\mathrm{pH}$-triggered drug releasing properties for active intracellular drug delivery. Mol Biosyst $1(3), 242-50$

Bae, Y., Nishiyama, N., Fukushima, S., Koyama, H., Yasuhiro, M. and Kataoka, K., 2005b. Preparation and biological characterization of polymeric micelle drug carriers with intracellular $\mathrm{pH}$-triggered drug release property: tumor permeability, controlled subcellular drug distribution, and enhanced in vivo antitumor efficacy. Bioconjug Chem 16(1), 122-30.

Bawa, P., Pillay, V., Choonara, Y.E. and Toit, L.C.D., 2009. Stimuli-responsive polymers and their applications in drug delivery Biomedical Materials 4(2).

Benns, J.M., Choi, J.S., Mahato, R.I., Park, J.S. and Kim, S.W., 2000. pH-sensitive cationic polymer gene delivery vehicle: $\mathrm{N}$ Ac-poly(L-histidine)-graft-poly(L-lysine) comb shaped polymer. Bioconjug Chem 11(5), 637-45.

Boussif, O., Delair, T., Brua, C., Veron, L., Pavirani, A. and Kolbe, H.V.J., 1999. Synthesis of Polyallylamine Derivatives and Their Use as Gene Transfer Vectors in Vitro. Bioconjugate Chemistry 10(5), 877-883.

Brannon-Peppas, L. and Blanchette, J.O., 2004. Nanoparticle and targeted systems for cancer therapy. Advanced Drug Delivery Reviews 56(11), 1649-1659.

Brown, M.D., Schatzlein, A.G. and Uchegbu, I.F., 2001. Gene delivery with synthetic (non viral) carriers. Int J Pharm 229(12), $1-21$.

Burt, H.M., Zhang, X., Toleikis, P., Embree, L. and Hunter, W.L., 1999. Development of copolymers of poly(DL-lactide) and methoxypolyethylene glycol as micellar carriers of paclitaxel. Colloids Surf., B: Biointerfaces 16(1-4), 161-171.

Couvreur, P. and Vauthier, C., 2006. Nanotechnology: intelligent design to treat complex disease. Pharm Res 23(7), 1417-50.

Dietz, G.P.H. and Bhr, M., 2004. Delivery of bioactive molecules into the cell: the Trojan horse approach. Molecular and Cellular Neuroscience 27(2), 85-131.

Domard, A. and Rinaudo, M., 2002. Chitosane: structure-properties relationship and biomedical applications. In: Polymeric Biomaterials. S. Dumitriu. CRC Press, Boca Raton: chapter 9.

Dufes, C., Uchegbu, I.F. and Schatzlein, A.G., 2005. Dendrimers in gene delivery. Adv Drug Deliv Rev 57(15), 2177-202. 
Duncan, R., 2003. The dawning era of polymer therapeutics. Nat Rev Drug Discov 2(5), 347-360.

Ehrlich, P., 1960. The collected papers of Paul Enrlich. Pergamon.London,

Farrell, L.L., Pepin, J., Kucharski, C., Lin, X., Xu, Z. and Uludag, H., 2007. A comparison of the effectiveness of cationic polymers poly-L-lysine (PLL) and polyethylenimine (PEI) for nonviral delivery of plasmid DNA to bone marrow stromal cells (BMSC). Eur J Pharm Biopharm 65(3), 388-97.

Forrest, M.L., Won, C.-Y., Malick, A.W. and Kwon, G.S., 2006. In vitro release of the mTOR inhibitor rapamycin from poly(ethylene glycol)-poly([epsilon]-caprolactone) micelles. Journal of Controlled Release 110,(2), 370-377.

Gaucher, G., Dufresne, M.-H., Sant, V.P., Kang, N., Maysinger, D. and Leroux, J.-C., 2005a. Block copolymer micelles: preparation, characterization and application in drug delivery. Journal of Controlled Release 109(1-3), 169-188.

Gaucher, G.E., Dufresne, M.-H.E., Sant, V.P., Kang, N., Maysinger, D. and Leroux, J.-C., 2005b. Block copolymer micelles: preparation, characterization and application in drug delivery. Journal of Controlled Release 109(1-3), 169-188.

Ge, H., Hu, Y., Jiang, X., Cheng, D., Yuan, Y., Bi, H. and Yang, C., 2002. Preparation, characterization, and drug release behaviors of drug nimodipine-loaded poly( $\varepsilon$-caprolactone)-poly(ethylene oxide)-poly( $\varepsilon$-caprolactone) amphiphilic triblock copolymer micelles. Journal of Pharmaceutical Sciences 91(6), 14631473.

Gillies, R.J., Raghunand, N., Garcia-Martin, M.L. and Gatenby, R.A., 2004. pH imaging. A review of $\mathrm{pH}$ measurement methods and applications in cancers. IEEE Eng Med Biol Mag 23(5), 57-64.

Gore, M.E., 2003. Adverse effects of gene therapy: Gene therapy can cause leukaemia: no shock, mild horror but a probe. Gene Ther 10(1), 4-4.

Gref, R., Minamitake, Y., Peracchia, M.T., Trubetskoy, V., Torchilin, V. and Langer, R., 1994. Biodegradable long-circulating polymeric nanospheres. Science 263(5153), 1600-1603.

Hayashi, H., Iijima, M., Kataoka, K. and Nagasaki, Y., 2004. pHSensitive Nanogel Possessing Reactive PEG Tethered Chains on the Surface. Macromolecules 37(14), 5389-5396.

Hruby, M., Konak, C. and Ulbrich, K., 2005. Polymeric micellar $\mathrm{pH}$-sensitive drug delivery system for doxorubicin. J Control Release 103(1), 137-48.

Ihm, J., Han, K., Han, L., Ahn, K., Han, D. and Cho, C., 2003. High Transfection Efficiency of Poly(4-vinylimidazole) as a New Gene Carrier. Bioconjugate Chem. 14,707-708.

Jain, A.K., Goyal, A.K., Mishra, N., Vaidya, B., Mangal, S. and Vyas, S.P., 2010. PEG-PLA-PEG block copolymeric nanoparticles for oral immunization against hepatitis B. Int J Pharm 387(1-2), 253-62.

Jeong, B., Bae, Y.H. and Kim, S.W., 2000. Drug release from biodegradable injectable thermosensitive hydrogel of PEGPLGA-PEG triblock copolymers. Journal of Controlled Release 63(1-2), 155-163.
Jeong, B. and Gutowska, A., 2002. Lessons from nature: stimuliresponsive polymers and their biomedical applications. Trends Biotechnol 20(7), 305-11.

Jeong, J.H., Kim, S.W. and Park, T.G., 2007. Molecular design of functional polymers for gene therapy. Progress in Polymer Science 32(11), 1239-1274.

Jevprasesphant, R., Penny, J., Jalal, R., Attwood, D., Mckeown, N.B. and D'emanuele, A., 2003. The influence of surface modification on the cytotoxicity of PAMAM dendrimers. Int $\mathbf{J}$ Pharm 252(1-2), 263-6.

Kataoka, K., Harada, A. and Nagasaki, Y., 2001. Block copolymer micelles for drug delivery: design, characterization and biological significance. Advanced Drug Delivery Reviews 47(1), 113-131.

Khandare, J. and Minko, T., 2006. Polymer-drug conjugates: Progress in polymeric prodrugs. Progress in Polymer Science 31(4), 359-397.

Kim, D., Lee, E.S., Oh, K.T., Gao, Z.G. and Bae, Y.H., 2008. Doxorubicin-Loaded Polymeric Micelle Overcomes Multidrug Resistance of Cancer by Double-Targeting Folate Receptor and Early Endosomal pH. Small 4(11), 2043-2050.

Kim, G.M., Bae, Y.H. and Jo, W.H., 2005a. pH-induced micelle formation of poly(histidine-co-phenylalanine)-block-poly(ethylene glycol) in aqueous media. Macromol Biosci 5(11), 111824.

Kim, I.-S., Jeong, Y.-I. and Kim, S.-H., 2000. Self-assembled hydrogel nanoparticles composed of dextran and poly(ethylene glycol) macromer. International Journal of Pharmaceutics 205(1-2), 109-116.

Kim, K., Kwon, S., Park, J.H., Chung, H., Jeong, S.Y., Kwon, I.C. and Kim, I.-S., 2005b. Physicochemical Characterizations of Self-Assembled Nanoparticles of Glycol Chitosan-deoxycholic Acid Conjugates. Biomacromolecules 6(2), 1154-1158.

Kim, S.Y., Shin, I.G., Lee, Y.M., Cho, C.S. and Sung, Y.K., 1998. Methoxy poly(ethylene glycol) and epsilon-caprolactone amphiphilic block copolymeric micelle containing indomethacin. II. Micelle formation and drug release behaviours. J Control Release 51(1), 13-22.

Kim, T.I., Seo, H.J., Choi, J.S., Jang, H.S., Baek, J.U., Kim, K. and Park, J.S., 2004. PAMAM-PEG-PAMAM: novel triblock copolymer as a biocompatible and efficient gene delivery carrier. Biomacromolecules 5(6), 2487-92.

Kircheis, R., Wightman, L. and Wagner, E., 2001. Design and gene delivery activity of modified polyethylenimines. Adv Drug Deliv Rev 53(3), 341-58.

Kissel, T., Li, Y. and Unger, F., 2002. ABA-triblock copolymers from biodegradable polyester A-blocks and hydrophilic poly(ethylene oxide) B-blocks as a candidate for in situ forming hydrogel delivery systems for proteins. Adv Drug Deliv Rev 54(1), 99-134.

Kumar, M.N.V.R., Muzzarelli, R.A.A., Muzzarelli, C., Sashiwa, H. and Domb, A.J., 2004. Chitosan Chemistry and Pharmaceutical Perspectives. Chemical Reviews 104(12), 6017-6084.

Kwon, G.S. and Kataoka, K., 1995. Block copolymer micelles as 
long-circulating drug vehicles. Adv. Drug Delivery Rev. 16(23), 295-309.

Kwon, G.S. and Okano, T., 1996. Polymeric micelles as new drug carriers. Advanced Drug Delivery Reviews 21(2), 107-116.

Langer, R., 1980. Invited review polymeric delivery systems for controlled drug release chem. eng. commun 6(1-3), 1-48.

Langer, R. and Peppas, N.A., 2003. Advances in biomaterials, drug delivery, and bionanotechnology. AIChE Journal 49(12), 2990-3006.

Lechardeur, D., Verkman, A.S. and Lukacs, G.L., 2005. Intracellular routing of plasmid DNA during non-viral gene transfer. Adv Drug Deliv Rev 57(5), 755-67.

Lee, E.S., Gao, Z. and Bae, Y.H., 2008a. Recent progress in tumor pH targeting nanotechnology. J Control Release 132(3), 16470.

Lee, E.S., Gao, Z., Kim, D., Park, K., Kwon, I.C. and Bae, Y.H., 2008b. Super $\mathrm{pH}$-sensitive multifunctional polymeric micelle for tumor $\mathrm{pH}(\mathrm{e})$ specific TAT exposure and multidrug resistance. J Control Release 129(3), 228-36.

Lee, E.S., Kim, D., Youn, Y.S., Oh, K.T. and Bae, Y.H., 2008c. A virus-mimetic nanogel vehicle. Angew Chem Int Ed Engl 47(13), 2418-21.

Lee, E.S., Na, K. and Bae, Y.H., 2003a. Polymeric micelle for tumor $\mathrm{pH}$ and folate-mediated targeting. Journal of Controlled Release 91(1-2), 103-113.

Lee, E.S., Na, K. and Bae, Y.H., 2005a. Doxorubicin loaded pHsensitive polymeric micelles for reversal of resistant MCF-7 tumor. Journal of Controlled Release 103(2), 405-418.

Lee, E.S., Na, K. and Bae, Y.H., 2005b. Super pH-Sensitive Multifunctional Polymeric Micelle. Nano Letters 5(2), 325-329.

Lee, E.S., Shin, H.J., Na, K. and Bae, Y.H., 2003b. Poly(-histidine)-PEG block copolymer micelles and $\mathrm{pH}$-induced destabilization. Journal of Controlled Release 90(3), 363-374.

Lee, H., Kim, T.H. and Park, T.G., 2002. A receptor-mediated gene delivery system using streptavidin and biotin-derivatized, pegylated epidermal growth factor. J Control Release 83,(1), 109-19.

Lehrman, S., 1999. Virus treatment questioned after gene therapy death. Nature 401(6753), 517-8

Lewin, M., Carlesso, N., Tung, C.H., Tang, X.W., Cory, D., Scadden, D.T. and Weissleder, R., 2000. Tat peptide-derivatized magnetic nanoparticles allow in vivo tracking and recovery of progenitor cells. Nat Biotechnol 18(4), 410-4.

Lin, W.J., Chen, Y.C., Lin, C.C., Chen, C.F. and Chen, J.W., 2006. Characterization of pegylated copolymeric micelles and in vivo pharmacokinetics and biodistribution studies. Journal of Biomedical Materials Research Part B: Applied Biomaterials 77B(1), 188-194.

Liu, Q. and Muruve, D.A., 2003. Molecular basis of the inflammatory response to adenovirus vectors. Gene Ther 10(11), 935-40

Liu, Z., Jiao, Y., Wang, Y., Zhou, C. and Zhang, Z., 2008. Polysaccharides-based nanoparticles as drug delivery systems. Adv Drug Deliv Rev 60(15), 1650-62.
Liua, F. and Urban, M., 2010. Recent advances and challenges in designing stimuli-responsive polymers Progress in Polymer Science 35(1-2), 3-23.

Lowman, A.M., Morishita, M., Kajita, M., Nagai, T. and Peppas, N.A., 1999. Oral delivery of insulin using $\mathrm{pH}$-responsive complexation gels. Journal of Pharmaceutical Sciences 88(9), 933937.

Midoux, P. and Monsigny, M., 1999. Efficient gene transfer by histidylated polylysine/pDNA complexes. Bioconjug Chem 10(3), 406-11.

Moghimi, S.M., Hunter, A.C. and Murray, J.C., 2001. Long-circulating and target-specific nanoparticles: Theory to practice. Pharmacological Reviews 53(2), 283-318.

Moghimi, S.M., Hunter, A.C. and Murray, J.C., 2005. Nanomedicine: current status and future prospects. FASEB J. 19(3), 311-330.

Mosqueira, V.C.F., Legrand, P., Morgat, J.-L., Vert, M., Mysiakine, E., Gref, R., Devissaguet, J.-P. and Barratt, G., 2001. Biodistribution of Long-Circulating PEG-Grafted Nanocapsules in Mice: Effects of PEG Chain Length and Density. Pharmaceutical Research 18(10), 1411-1419.

Na, K., Lee, E.S. and Bae, Y.H., 2003. Adriamycin loaded pullulan acetate/sulfonamide conjugate nanoparticles responding to tumor $\mathrm{pH}$ : $\mathrm{pH}$-dependent cell interaction, internalization and cytotoxicity in vitro. J Control Release 87(1-3), 3-13.

Na, K., Lee, E.S. and Bae, Y.H., 2007. Self-Organized Nanogels Responding to Tumor Extracellular pH: pH-Dependent Drug Release and in Vitro Cytotoxicity against MCF-7 Cells. Bioconjugate Chemistry 18(5), 1568-1574.

Na, K., Lee, K.H. and Bae, Y.H., 2004. pH-sensitivity and pHdependent interior structural change of self-assembled hydrogel nanoparticles of pullulan acetate/oligo-sulfonamide conjugate. Journal of Controlled Release 97(3), 513-525.

Na, K., Park, K.-H., Kim, S.W. and Bae, Y.H., 2000. Self-assembled hydrogel nanoparticles from curdlan derivatives: characterization, anti-cancer drug release and interaction with a hepatoma cell line (HepG2). Journal of Controlled Release 69(2), 225-236.

Neuse, E.W., 2008. Synthetic polymers as drug-delivery vehicles in medicine. Met Based Drugs 2008, 469-531.

Oh, K., Yin, H., Lee, E. and Beae, Y., 2007a. Polymeric nanovehicles for anticancer drugs with triggering release mechanisms. Journal of Materials Chemistry 17.

Oh, K.T., Baik, H.J., Lee, A.H., Oh, Y.T., Youn, Y.S. and Lee, E.S., 2009a. The reversal of drug-resistance in tumors using a drugcarrying nanoparticular system. International journal of molecular sciences 10(9), 3776-92.

Oh, K.T., Bronich, T.K., Kabanov, V.A. and Kabanov, A.V., $2007 \mathrm{~b}$. Block polyelectrolyte networks from poly(acrylic acid) and poly(ethylene oxide): sorption and release of cytochrome C. Biomacromolecules 8(2), 490-7.

Oh, K.T., Kim, D., You, H.H., Ahn, Y.S. and Lee, E.S., 2009b. pHsensitive properties of surface charge-switched multifunctional polymeric micelle. Int J Pharm 376(1-2), 134-40.

J. Pharm. Invest., Vol. 40, Special issue (2010) 
Oh, K.T. and Lee, E.S., 2008. Cancer-associated pH-responsive tetracopolymeric micelles composed of poly(ethylene glycol)poly(L-histidine)-poly(L-lactic acid)-poly(ethylene glycol). Polymers for Advanced Technologies 19(12), 1907-1913.

Oh, K.T., Oh, Y.T., Oh, N.-M., Kim, K., Lee, D.H. and Lee, E.S., 2009c. A smart flower-like polymeric micelle for pH-triggered anticancer drug release. International Journal of Pharmaceutics 375(1-2), 163-169.

Oh, N.M., Oh, K.T., Baik, H.J., Lee, B.R., Lee, A.H., Youn, Y.S. and Lee, E.S., 2010. A self-organized 3-diethylaminopropylbearing glycol chitosan nanogel for tumor acidic $\mathrm{pH}$ targeting: In vitro evaluation. Colloids and Surfaces B: Biointerfaces 78(1), 120-126.

Oishi, M., Hayashi, H., Iijima, M. and Nagasaki, Y., 2007. Endosomal release and intracellular delivery of anticancer drugs using $\mathrm{pH}$-sensitive PEGylated nanogels. Journal of Materials Chemistry 17(35), 3720-3725.

Park, J.H., Lee, S., Kim, J.-H., Park, K., Kim, K. and Kwon, I.C., 2008. Polymeric nanomedicine for cancer therapy. Progress in Polymer Science 33(1), 113-137.

Park, K., Lee, G.Y., Kim, Y.-S., Yu, M., Park, R.-W., Kim, I.-S., Kim, S.Y. and Byun, Y., 2006a. Heparin-deoxycholic acid chemical conjugate as an anticancer drug carrier and its antitumor activity. Journal of Controlled Release 114(3), 300-306.

Park, T.G., Jeong, J.H. and Kim, S.W., 2006b. Current status of polymeric gene delivery systems. Adv Drug Deliv Rev 58(4), 467-86.

Petersen, H., Fechner, P.M., Martin, A.L., Kunath, K., Stolnik, S., Roberts, C.J., Fischer, D., Davies, M.C. and Kissel, T., 2002. Polyethylenimine-graft-poly(ethylene glycol) copolymers: influence of copolymer block structure on DNA complexation and biological activities as gene delivery system. Bioconjug Chem 13(4), 845-54.

Ratner, B.D. and Hoffman, A.S., 1976. Synthetic hydrogels for biomedical applications. In: . In: Hydrogels for Medical and Related Applications. J.D. Andrade. American Chemical Society, Washington, DC 1-36.

Ravi Kumar, M.N.V., 2000. A review of chitin and chitosan applications. Reactive and Functional Polymers 46(1), 1-27.

Ruenraroengsak, P., Cook, J.M. and Florence, A.T., 2010. Nanosystem drug targeting: Facing up to complex realities. Journal of Controlled Release 141(3), 265-276.

Schmaljohann, D., 2006. Thermo- and pH-responsive polymers in drug delivery. Adv Drug Deliv Rev 58(15), 1655-70.

Shin, I.G., Kim, S.Y., Lee, Y.M., Cho, C.S. and Sung, Y.K., 1998. Methoxy poly(ethylene glycol)/epsilon-caprolactone amphiphilic block copolymeric micelle containing indomethacin. I. Preparation and characterization. J Control Release 51(1), 1-11.

Son, Y.J., Jang, J.-S., Cho, Y.W., Chung, H., Park, R.-W., Kwon, I.C., Kim, I.-S., Park, J.Y., Seo, S.B., Park, C.R. and Jeong, S.Y., 2003. Biodistribution and anti-tumor efficacy of doxorubicin loaded glycol-chitosan nanoaggregates by EPR effect. Journal of Controlled Release 91(1-2), 135-145.

Stuart, M.A.C., Huck, W.T.S., Genzer, J., Muller, M., Ober, C.,
Stamm, M., Sukhorukov, G.B., Szleifer, I., Tsukruk, V.V., Urban, M., Winnik, F., Zauscher, S., Luzinov, I. and Minko, S., 2010. Emerging applications of stimuli-responsive polymer materials. Nat Mater 9(2), 101-113.

Stubbs, M., Mcsheehy, P.M., Griffiths, J.R. and Bashford, C.L., 2000. Causes and consequences of tumour acidity and implications for treatment. Mol Med Today 6(1), 15-9.

Sun, J.Y., Anand-Jawa, V., Chatterjee, S. and Wong, K.K., 2003. Immune responses to adeno-associated virus and its recombinant vectors. Gene Ther 10(11), 964-76.

Tannock, I.F. and Rotin, D., 1989. Acid pH in tumors and its potential for therapeutic exploitation. Cancer Res 49(16), 4373-84.

Torchilin, V.P., 2000. Drug targeting. European Journal of Pharmaceutical Sciences 11,(Supplement 2), S81-S91.

Torchilin, V.P., 2002. PEG-based micelles as carriers of contrast agents for different imaging modalities. Adv Drug Deliv Rev 54(2), 235-52.

Uhrich, K.E., Cannizzaro, S.M., Langer, R.S. and Shakesheff, K.M., 1999. Polymeric systems for controlled drug release. Chem Rev 99(11), 3181-98.

Van Vlerken, L.E., Vyas, T.K. and Amiji, M.M., 2007. Poly(ethylene glycol)-modified nanocarriers for tumor-targeted and intracellular delivery. Pharm Res 24(8), 1405-14.

Vandevord, P.J., Matthew, H.W.T., Desilva, S.P., Mayton, L., Wu, B. and Wooley, P.H., 2002. Evaluation of the biocompatibility of a chitosan scaffold in mice. Journal of Biomedical Materials Research 59(3), 585-590.

Wittmar, M., Ellis, J.S., Morell, F., Unger, F., Schumacher, J.C., Roberts, C.J., Tendler, S.J.B., Davies, M.C. and Kissel, T., 2005. Biophysical and Transfection Studies of an AmineModified Poly(vinyl alcohol) for Gene Delivery. Bioconjugate Chemistry 16(6), 1390-1398.

Xu, P., Van Kirk, E.A., Li, S., Murdoch, W.J., Ren, J., Hussain, M.D., Radosz, M. and Shen, Y., 2006. Highly stable core-surface-crosslinked nanoparticles as cisplatin carriers for cancer chemotherapy. Colloids and Surfaces B: Biointerfaces 48(1), 50-57.

Yamaoka, T., Tabata, Y. and Ikada, Y., 1994. Distribution and tissue uptake of poly(ethylene glycol) with different molecular weights after intravenous administration to mice. Journal of Pharmaceutical Sciences 83(4), 601-606.

Yokoyama, M., Fukushima, S., Uehara, R., Okamoto, K., Kataoka*, K., Sakurai, Y. and Okano, T., 1998. Characterization of physical entrapment and chemical conjugation of adriamycin in polymeric micelles and their design for in vivo delivery to a solid tumor. Journal of Controlled Release 50(13), 79-92.

Yu, S., Hu, J., Pan, X., Yao, P. and Jiang, M., 2006. Stable and pHSensitive Nanogels Prepared by Self-Assembly of Chitosan and Ovalbumin. Langmuir 22(6), 2754-2759.

Yusa, Shin, I., Sugahara, Makoto, Endo, Tatsuya, Morishima and Yotaro, 2009. Preparation and Characterization of a $\mathrm{pH}-$ Responsive Nanogel Based on a Photo-Cross-Linked Micelle Formed From Block Copolymers with Controlled Structure. 
American Chemical Society.Washington, DC, ETATS-UNIS, Zhang, S., Xu, Y., Wang, B., Qiao, W., Liu, D. and Li, Z., 2004. Cationic compounds used in lipoplexes and polyplexes for gene delivery. J Control Release 100(2), 165-80.
Zhang, Y. and Zhuo, R.-X., 2005. Synthesis and in vitro drug release behavior of amphiphilic triblock copolymer nanoparticles based on poly (ethylene glycol) and polycaprolactone. Biomaterials 26(33), 6736-6742. 